\title{
Nasopharyngeal Carcinoma in childhood: Analysis of a Series of 64 Patients treated with Combined Chemotherapy and Radiotherapy
}

\author{
K Mouden ${ }^{1}$, M El kababri ${ }^{2}$, A Kili ${ }^{2}$, S El majjaoui ${ }^{1}$, H El kacemi ${ }^{1}$, B el kebdani ${ }^{1}$, Hessissen $^{2}$, M El khorassani $^{2}$, \\ M Khattab ${ }^{2}$ and N Benjaafar ${ }^{1}$ \\ ${ }^{1}$ Department of Radiotherapy, University Mohammed V Rabat, Morocco \\ ${ }^{2}$ Center of Pediatric Hematology and Oncology, University Mohammed V Rabat, Morocco
}

Submission: January 09, 2018; Published: January 26, 2018

"Correspondence Address: Karima Mouden, Radiation Oncologist, National Institute Of Oncology Rabat, Morocco,

Email: moudenkarima@gmail.com

\begin{abstract}
Background: The aim of our study is to investigate the epidemiological, clinical, radiological, therapeutic particularities of the nasopharyngeal carcinoma (NPC) in children, and to determine prognostic factors correlated with outcome and features of a series of 64 cases collected in the National Institute of Oncology and Center of Pediatric Hematology Oncology, in Rabat.

Patients and Methods: A total of 64 patients with NPC were treated in the Center of Pediatric Hematology and Oncology in Rabat, from 2001 to 2010. They were retrospectively analyzed. Overall survival (OS) and disease-free survival (DFS) were calculated.

Results: Most patients were males (76.6\%). Median age was 12 years. The main presenting symptoms were neck mass (82.8\%), tinnitus/ hearing loss (60.9\%), bloody nasal discharge (50\%), headache (53.1\%) and nasal obstruction (35.9\%). Stage I, II, III, IVA, IVB and IVC patients accounted for $0 \%, 1.6 \%, 42.2 \%, 25 \%, 28.1 \%$ and $3.1 \%$, respectively. All patients were treated by neoadjuvant chemotherapy. The complete response rate to chemotherapy was $78.1 \%$. All patients were treated by radiotherapy: 70 Gy to primary tumors, 50 Gy to cervical lymph nodes and $70 \mathrm{~Gy}$ to lymphadenopathy. Locoregional relapses were observed in 7 patients, with a median delay of 62.75 months from the end of treatment (4.1-156.9 months). The 2-, 5- and 10- year overall survival (OS) rates were $98.4 \%, 82.3 \%$ and $75.4 \%$, respectively. Disease-free survival (DFS) was $73 \%, 62.7 \%$ at 5 and 10 years respectively. The main long-term complications of therapy were trismus (59.4\%), hearing loss (51.6\%), xerostomia (50\%) and neck fibrosis $(37.5 \%)$.
\end{abstract}

Conclusion: The majority of patients were diagnosed at advanced stages. Children and adolescents with NPC had excellent survival except metastatic disease. The TNM stage was the most relevant prognostic factor.

Keywords: Nasopharyngeal carcinoma; Childhood; Radiation; Chemotherapy

Abbreviations: NPC: Nasopharyngeal Carcinoma; OS: Overall Survival; DFS: Disease-Free Survival; WHO: World Health Organization; CT: Computed Tomography; BEC: Bleomycin Epirubicin Cisplatin; CR: Complete Response; IMRT: Intensity Modulated Radiation Therapy; EBV: Epstein Barr Virus

\section{Background}

The frequency of nasopharyngeal carcinoma (NPC) varies extensively with age, ethnic and geographical origin [12]. There is a high incidence of NPC in Southern China, the cancer is generally found in patients over 40 years of age and is uncommon in childhood $(<1 \%)$ [2]. In North Africa, NPC constitutes $5-10 \%$ of childhood tumors. Undifferentiated NPC is the most frequent histological type in childhood. It is classically associated with a more advanced loco regional stage and with more frequent distant metastases than in adult [2,6-8]. However, the 5-year disease-free survival does not seem to differ from that of adult and varies from 30 to $60 \%$ [3-7]. Standard therapy for NPC in children has generally followed the guidelines established for adults and is based on radiotherapy. Successful randomised trials $[9,10]$, have led to the increased use of chemotherapy in combination with radiotherapy, but data on treatment outcomes in children are sparse. Therefore, we felt it important to examine specific survival and late toxicity in children treated for NPC. The aim of our study is to determine prognostic factors correlated with outcome and epidemiological features in Moroccan population.

\section{Patients and Methods}

A total of 64 young patients with NPC were treated in our institution between January 2001 and December 2010 


\section{Cancer Therapy \& Oncology International Journal}

representing $2 \%$ of all pediatric cancer cases. Cutoff date of analysis was October 2014. They represented $2.5 \%$ of all patients with NPC treated during the same period. There is a predominance of males; sex ratio (male/female (M/F)) was 3.26. All patients had cervical lymphadenopathy. Histological diagnosis was made according to the World Health Organization (WHO) classification on biopsies of the primary tumor. All patients had an undifferentiated carcinoma (WHO type 3). All patients had a clinical history and examination, dental care with topical fluoride protection, computed tomography (CT) of the head and neck, a chest X-ray, abdominal ultrasonography, a bone scan, a full blood count and routine biochemical investigations.

As NPC staging has evolved over the past decades, we attempted to re-stage all patients according to the most recent version of the American Joint Committee on Cancer Seventh Edition (AJCC 7) NPC staging classification using the available clinical information and the original radiology reports. All patients were treated with three cycles of neoadjuvant chemo $\neg$ therapy every 21 days combining bleomycine $(12 \mathrm{mg} /$ $\mathrm{m}^{2} /$ day during 5 days), epirubicin $(70 \mathrm{mg} / \mathrm{m} 2$, day 1$)$, cisplatin (100 mg/m2, day 1) called BEC regimen, and followed by concurrent chemo radiation containing cisplatin $30 \mathrm{mg} / \mathrm{m}^{2} /$ week .

Three-dimensional radiotherapy was used (3D). The radiation was delivered to a total dose of 70 Gy to nasopharynx and involved nodes and 50 Gy to the remainder cervical areas, 2 Gy/fraction in 7 weeks. Median of total duration of radiotherapy was 78 days (46-134). It was quite different among patients; because there were 46 children delayed the treatment on

Table 1: patient characteristics.

\begin{tabular}{|c|c|}
\hline Characteristic & $\mathrm{N}(\%$ or range $)$ \\
\hline \multicolumn{2}{|c|}{ Gender } \\
\hline Male & $49(76 \%)$ \\
\hline Female & $15(24 \%)$ \\
\hline Age, years (Middle) & $12(7-16)$ \\
\hline \multicolumn{2}{|c|}{ Presenting Symptom } \\
\hline Neck mass & $53(82 \%)$ \\
\hline Trismus & $26(41 \%)$ \\
\hline Tinnitus/Hearing loss & $39(61 \%)$ \\
\hline Nasal bloody discharge & $32(50 \%)$ \\
\hline Headache & $34(53 \%)$ \\
\hline Nasal obstruction & $23(36 \%)$ \\
\hline Pathologic type: Undifferentiated non keratinizing carcinoma & $64(100 \%)$ \\
\hline \multicolumn{2}{|c|}{ T stage } \\
\hline $\mathrm{T} 1$ & $2(3 \%)$ \\
\hline $\mathrm{T} 2$ & $6(9 \%)$ \\
\hline $\mathrm{T} 3$ & $33(52 \%)$ \\
\hline $\mathrm{T} 4$ & $23(36 \%)$ \\
\hline
\end{tabular}

account of acute toxicities. Photon beam of cobalt-60 gamma rays and linear accelerator high energy $\mathrm{x}$-rays ( 6 megavolts) was used.

Response to treatment was assessed after the third cycle of chemotherapy by head-and-neck examination and a CT scan of the nasopharynx; 2-3 months after the end of the radiotherapy a further head-and-neck examination and a new CT scan of the naso $\neg$ pharynx were performed. Follow-up was every 3 months for the first 2 years, every 6 months the next 2 years, and then every year. Toxicity and responses were evaluated according to WHO criteria. Overall survival (OS) and disease-free survival (DFS) were obtained according to the Kaplan-Meier method, and compared with the log-rank test. Prognostic factors were analysed using the Cox proportional hazards regression model. Statistical significance was assumed for a two-tailed $\mathrm{p}$ value < 0.05 .

\section{Results}

\section{Patient Characteristics}

The characteristics of the patients are described in Table 1. The median age at diagnosis was 12 years (range, 7-16 years). Most patients were male (76\%). The median time interval between the first presentation and diagnosis was five months (range, 1-13 months). The most common presenting symptom was neck mass, followed by tinnitus/hearing loss, headache, bloody nasal discharge, and nasal obstruction. The majority of patients had advanced T stage, regional lymph node metastases, and high stage. Two patients (3\%) had distant metastases at diagnosis (lung for one patient, liver and bone for the second patient). 


\section{Cancer Therapy \& Oncology International Journal}

\begin{tabular}{|c|c|}
\hline No & $5(8 \%)$ \\
\hline N1 & $12(19 \%)$ \\
\hline N2 & $28(44 \%)$ \\
\hline N3a & $17(26 \%)$ \\
\hline $\mathrm{N} 3 \mathrm{~b}$ & $2(3 \%)$ \\
\hline \multicolumn{2}{|l|}{ M stage } \\
\hline M0 & 62 \\
\hline M1 & 2 \\
\hline \multicolumn{2}{|c|}{ TNM stage } \\
\hline I & 0 \\
\hline II & $1(1,6 \%)$ \\
\hline III & $27(42,2 \%)$ \\
\hline IVA & $16(25 \%)$ \\
\hline IVB & $18(28,1 \%)$ \\
\hline IVC & $2(3,1 \%)$ \\
\hline \multicolumn{2}{|c|}{ Response to Traitement } \\
\hline Complete response & $45(70,3 \%)$ \\
\hline Progression & $12(18,8 \%)$ \\
\hline Recurrence & $7(10,9 \%)$ \\
\hline \multicolumn{2}{|c|}{ Late Toxicity } \\
\hline Trismus & $38(59,4 \%)$ \\
\hline Hearing Loss & $33(51,6 \%)$ \\
\hline Xerostomia & $32(50 \%)$ \\
\hline Neck Fibrosis & $24(37,5 \%)$ \\
\hline Encephalopathy & $3(4,7 \%)$ \\
\hline
\end{tabular}

\section{Response to treatment}

Response to therapy was assessed three to six months after completion of treatment based on clinical examination and imaging (CT). 45 patients (78.1\%) exhibited complete response (CR).

\section{Survival and Recurrence}

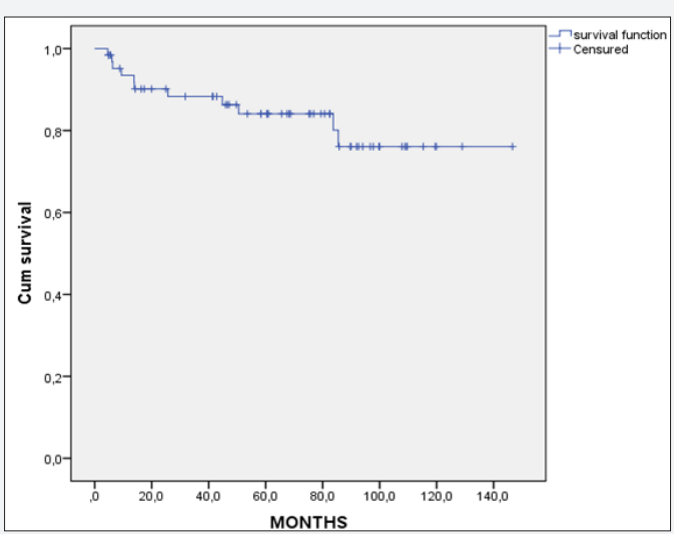

Figure 1: Overall survival curve for the whole cohort.

The average follow-up time was 65.5 months (range, 4.6156.9 months). 6 patients $(9.1 \%)$ were lost to follow-up. 12 patients $(18.2 \%)$ died , and 46 patients (71.9\%) were still alive.
2 patients were diagnosed with metastasis before treatment died after 3 cycles of chemotherapy and before radiotherapy .For the whole cohort, the 5- and 10- year OS was $82.3 \%$ and $75.4 \%$, respectively (Figure 1). The 5 - and 10 - year DFS was $73 \%$ and $62.7 \%$ respectively (Figure 2). Relapses were observed in 7 patients, with a median delay of 62.7 months from the end of treatment (4.1-156.9 months). Disease-free survival (DFS) was $89.5 \%, 80.4 \%$ at 5 and 10 years respectively.

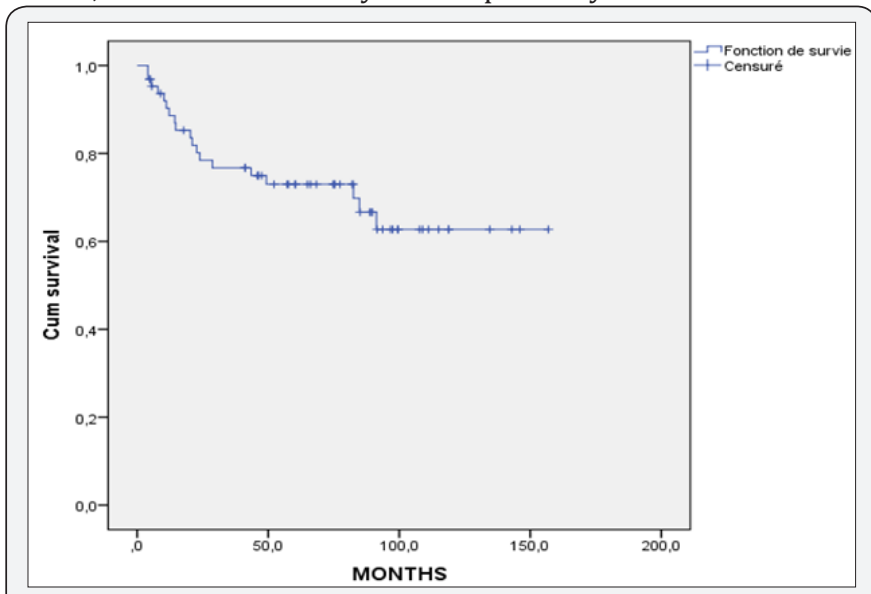

Figure 2: Disease free survival curve for the whole cohort. 


\section{Cancer Therapy \& Oncology International Journal}

\section{Prognostic Factors}

For the univariate analysis, we study prognostic variables: tumor (T) stage, node (N) stage, metastasis (M) stage, tumor node metastasis (TNM) stage, gender and age (Table 2). The 2 patients with metastatic disease at diagnosis died within five months. Gender demonstrated a significant influence on overall survival (Figure 3).

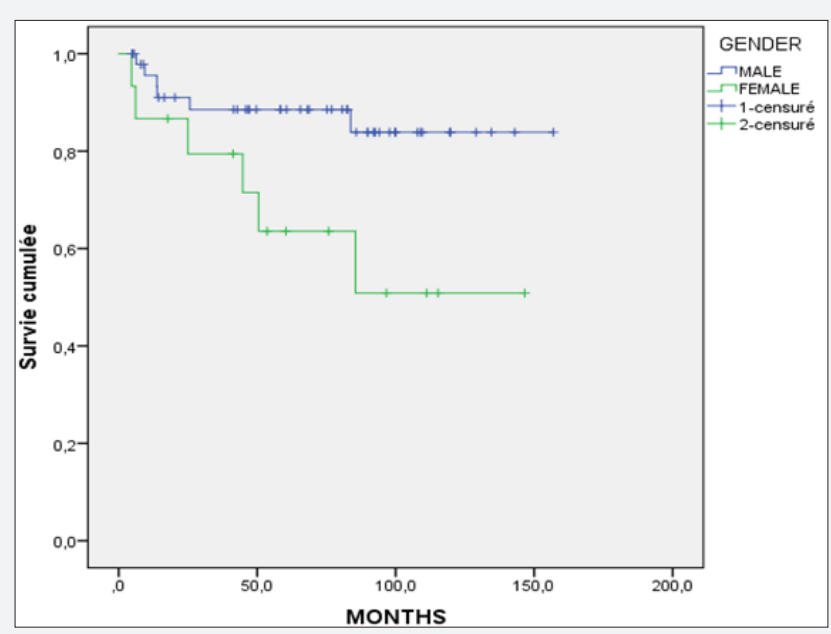

Figure 3 : Overall survival curve according to the gender.

Table 2: 5-year overall survival rate and disease free survival according to prognostic factors.

\begin{tabular}{|c|c|c|c|c|c|}
\hline \multirow{2}{*}{\multicolumn{2}{|c|}{ Prognostic Factors }} & \multirow{2}{*}{$\begin{array}{c}\text { Overall Survival } \\
\text { 5-year OS }\end{array}$} & \multirow[b]{2}{*}{$\mathbf{p}$} & \multicolumn{2}{|c|}{ Disease Free Survival } \\
\hline & & & & 5-year DFS & $\mathbf{P}$ \\
\hline \multirow{2}{*}{ Gender } & Male & $88.8 \% 0.026$ & \multirow{2}{*}{0.026} & $78 \%$ & \multirow{2}{*}{0.17} \\
\hline & Female & $69.30 \%$ & & $57.80 \%$ & \\
\hline \multirow{2}{*}{ Age, years (middle) } & $<12$ & $86.60 \%$ & \multirow{2}{*}{0.81} & $69 \%$ & \multirow{2}{*}{0.34} \\
\hline & $>12$ & $77.10 \%$ & & $77.30 \%$ & \\
\hline \multirow{3}{*}{ T stage } & $\mathrm{T} 2$ & $100 \%$ & \multirow{3}{*}{0.53} & $83.30 \%$ & \multirow{3}{*}{0.61} \\
\hline & T3 & $75.6 \%$ & & $64.50 \%$ & \\
\hline & $\mathrm{T} 4$ & $85.00 \%$ & & $81.30 \%$ & \\
\hline \multirow{4}{*}{ N stage } & & $83.30 \%$ & \multirow{4}{*}{0.52} & & \multirow{4}{*}{0.47} \\
\hline & N1 & & & $83.30 \%$ & \\
\hline & $\mathrm{N} 2$ & $82.7 \%$ & & $69.40 \%$ & \\
\hline & N3 & $74.90 \%$ & & $64.40 \%$ & \\
\hline \multirow{2}{*}{ TNM stage } & III & $82.60 \%$ & \multirow{2}{*}{0.9} & $72.30 \%$ & \multirow{2}{*}{0.34} \\
\hline & IV & $81.70 \%$ & & $76 \%$ & \\
\hline
\end{tabular}

\section{Morbidities}

The main long-term complications of therapy were trismus (59.4\%), hearing loss (51.6\%), xerostomia (50\%), neck fibrosis $(37.5 \%)$ and radiation encephalopathy $(4.7 \%)$.

\section{Discussion}

The incidence of childhood nasopharyngeal carcinoma (NPC) varies greatly according to racial and geographical factors $[1,11]$. In general it represents less than $1 \%$ [12] of all childhood malignant tumors but constitutes 20 to $50 \%$ of pediatric malignancies of the nasopharynx [13]. In North Africa and Mediterranean basin, 5-10\% of NPC cases occur in children [13]. One remarkable difference between Mediterranean and Asian NPC is age distribution of patients. While a unimodal peak at 5060 years of age exists in endemic countries, an additional minor peak appears at 10-20 years of age exists at Mediterranean region countries [13]. 


\section{Cancer Therapy \& Oncology International Journal}

In this present study, nasopharynx cancer in children present $2.5 \%$ of all cases of nasopharynx cancer treated in our hospital. Although the mean age at diagnosis is between 5060 years, NPC may occur at almost any age $[14,15]$. A bimodal age incidence graph with a first small peak in late childhood is observed in some populations $[4,16,17,18$,]. Children with NPC almost always have the undifferentiated variant (WHO Type3) of disease, which is closely related to a higher rate of advanced loco regional disease and distant metastasis $[7,19,20]$. In our series, stages $\mathrm{T} 1$ and $\mathrm{T} 2$, N0 and N1 represent respectively $12.5 \%$ and $26.6 \%$ of cases. Despite a high incidence of advanced loco regional disease the overall survival rates do not significantly differ from adults and the 5-year disease-free survival rate is between $29-60 \%$ in reported pediatric series $[7,16,20]$. The fiveyear disease-free survival rate is $73 \%$ in our series $[5-16,18]$.

Magnetic resonance imaging (MRI) is the preferred staging method. However, our patients were staging with CT of the head and neck because the MRI was not made. Staging has been a prognostic factor in patients with nasopharyngeal carcinoma, with advanced $\mathrm{T}$ or $\mathrm{N}$ stages reported to be associated with adverse outcome [7,21-23]. Because the majority of patients in this series had T3, 4 and/or N3 disease, comparison for outcome between $\mathrm{T}$ and $\mathrm{N}$ stages would not be feasible. Analysis of the 5 -OS for our patients indicates that stages $\mathrm{T}$ or $\mathrm{N}$ were not significant because of a few cases and a total of 6 patients (9.1\%) were lost to follow-up.

Standard therapy for nasopharyngeal carcinoma in children has generally followed the guidelines established for adults, which consist of high-dose radiation to nasopharynx and involved cervical node areas as well as moderate doses to uninvolved cervical node sites using Intensity Modulated Radiation Therapy (IMRT). In our study, all patients were treated using three dimensional radiotherapy.BEC regimen was not a routine regimen for NPC. Actually, the Center of Pediatric Hematology and Oncology does not use it for patient. Although high-dose radiotherapy in children can be curative but it has been associated with significant morbidity among long term survivors [7,12,20,24-26]. Time from the onset of the NPC symptoms to the beginning of treatment varies, from a few months to half a year $[27,28]$.

Radiation therapy is an obligatory element in the treatment of NPC. A marked correlation exists between radiation dose and tumor response $[4,29]$. With a radiation dose of $>60 \mathrm{~Gy}$, a relapse free survival time of 5 years was achieved in $70 \%$ of patients with lower disease (T1 and T2), compared with only $20 \%$ of patients whose disease was classified as T3 or T4 [30]. In a study by Quin et al. [31] the high risk patient group treated with irradiation of the primary tumor had a $35 \%$ rate of 5 -year RFS with doses of 50-59 Gy and a rate of 54\% with a dose of 70 Gy. The data also showed that $18.4 \%$ of patients who received more than 60 Gy developed radiation encephalopathy, and the incidence of encephalopathy increased with the dose delivered to the primary tumor.

Other authors have reported endocrine abnormalities, impairment of growth, trismus, neck fibrosis, and otitis media in $15-50 \%$ of their patients [20,25,29,32]. Side Effects Data in the literature demonstrate that the incidence of long term side effects of radiation is very high in survivors of childhood NPC. Despite good local tumor control after high dose radiation therapy, many patients have distant metastases. A study by Sham et al. [4] found a poor prognosis with radiation alone, due to the early appearance of metastases. Almost $57 \%$ of relapse patients in the high risk group developed distant metastases. In Table 2, which shows the treatment results given by various authors, the proportion of local relapses and distant metastases and the time between diagnosis and the appearance of metastases are given. NPC metastases emerge in the first 2 years after diagnosis. In patients with advanced tumors (up to $80 \%$ of young patients), occult metastases are often present at diagnosis, so that, although the radiation sensitive primary tumor can generally be effectively controlled by local therapy, distant metastases can present independently.

\section{Conclusion}

In summary, the current study is the largest one that dealt with childhood NPC. We confirmed that NPC in children and adolescents has several different features from its adult counterpart. Young NPC patients tend to be diagnosed at advanced stage, while the prognosis is satisfactory except in metastatic disease. The overwhelming majority of this population has undifferentiated carcinoma. The vast majority of relapse is distant metastasis occurring over a short period of time after treatment. The tumor responds well to RT-based multimodality treatment; however, the dose schedule requires optimization by more randomized multiาinstitutional studies. Efforts toward early diagnosis and decreasing long-term morbidity of treatment are of great importance. With advanced imaging technology facilities to accurately diagnose this disease at an earlier stage and with new radiation technology to improve dose distribution, the outcome of this disease will be certainly improved further. The emerging molecular-targeted therapy cetuximab, for example, is promising but is still under investigation [33]. Given a close relationship between EBV and NPC occurrence, immunotherapy with cytotoxic $\mathrm{T}$ cells [34] and interferon [35], which target EBV or EBV-associated cancer cells or molecules, could possibly yield clinical benefits in some patients. The association of these new agents and RT will certainly become the basis of future therapeutic approaches. Several questions need to be answered: What is the optimal dose of RT in the IMRT era? What is the most beneficial chemotherapy method: induction or concurrent? What is the contribution of the new agents? How can we manage recurrent/metastatic disease? Future studies should focus on these points. 


\section{Cancer Therapy \& Oncology International Journal}

\section{Competing Interests}

The authors declare that they have no competing interests.

\section{Author's Contributions}

$\mathrm{KM}, \mathrm{ME}, \mathrm{AK}$ and SE were the major contributors in writing the manuscript. HE, TK, LH, ME, MK and NB assisted in the data collection and the preparation of the manuscript. All authors read and approved the final manuscript.

\section{Acknowledgement}

All authors are thankful for providing the necessary facilities for the preparation of the manuscript. Special thanks are due to the Faculty of Medicine and Pharmacy of Rabat, the source(s) of funding for all authors.

\section{Ethics Approval and Consent to Participate}

Informed consent was not obtained from each participant because this was a retrospective study.

\section{Consent for Publication}

Consent to publish was not obtained because an individual person's information is not included in this study.

\section{Availability of Data and Materials}

We did not use particular software or databases for this study.

\section{Funding}

This study was not supported by any funding resource.

\section{References}

1. Deutsch MS, Mercado R, Person JA (1978) Cancer of the nasopharynx in children. Cancer $41: 1128-1133$.

2. Huang TB (1990) Cancer of nasopharynx in childhood. Cancer 66(5): 968-971.

3. Berry MPS, Smith CR, Brown TC, Jenkin DD, Rider WD (1980) Nasopharyngeal carcinoma in the young. Int J Radiat Oncol BiolPhys 6: 415-421.

4. Sham JST, Poom YF, Wei WI, Choy D (1990) Nasopharyngeal carcinoma in young patients. Cancer $65: 2606-2610$.

5. Cammoun MS, Houissa T, Ellouz R (1976) Le cancer de l'enfant en Tunisie; Frequence relative des differents types histologiques. A propos de 582 observations. La Tunisie Medicale 5: 765-771.

6. Attia AB, Maalej M, Ellouz R (1986) Results of radiotherapy and adjuvant chemotherapy in the treatment of nasopharyngeal cancer in young patients-a review of 28 cases. Int J Radiat Oncol Biol Phys 4 161-167.

7. Ingersoll L, Woo SY, Donaldson S, Giesler J, Maor MH, et al. (1990) Nasopharyngeal carcinoma in the young. A combined M-D Anderson and Stanford Experience. Int J Radiat Oncol Biol Phys 19(4): 881-887.

8. Kim TH, McLaren J, Alvarado CS, Wyly JB, Crocker I, et al. (1989) Adjuvant chemotherapy for advanced nasopharyngeal carcinoma in childhood. Cancer 63(10): 1922-1926.

9. International Nasopharyngeal Cancer Study Group (1996) Preliminary results of the randomising trial comparing neoadjuvant chemotherapy (cisplatinum, epirubicin, bleomycin) plus radiotherapy vs. radiotherapy alone in stage IV $(=\mathrm{N} 2, \mathrm{M} 0)$ undifferentiated nasopharyngeal cancer. Int J Radiat Oncol Biol Phys 35(3): 463-469.

10. Al-Sarraf M, Le Blanc M, Giri S, Fu KK, Cooper J, et al. (1996) Chemoradiotherapy versus radiotherapy in patients with advanced nasopharyngeal cancer: phase III Randomized Intergroup study 0099. J Clin Oncol 16: 12101217.

11. Plowman PN (1992) Rare tumors. In: Plowman, P. N., Pinkerton, C. R., eds. Paediatric Oncology. Clinical Practice and Controversies. Cambridge, Chapman and Hall University Press, UK, pp. 446-459.

12. Healy GB (1980) Malignant tumors of the head and neck in children Diagnosis and treatment Otolaryngol Clin North Am 13(3): 483-488.

13. Afqir S, Ismaili N, Alaoui K, Ahid S, Lotz JP (2009) Nasopharyngeal carcinoma in adolescents: a retrospective review of 42 patients. Eur Arch Otorhinolaryngol 266(11): 1767-1773.

14. Altun M, Fandi A, Dupuis O, Cvitkovic E, Krajina Z, et al. (1995) Undifferentiated nasopharyngeal cancer (UCNT): Current diagnostic and therapeutic aspects. Int J Radiat Oncol Biol Phys 32(3): 859-877.

15. Fandi A, Altun M, Azli N, Armand JP, Cvitkovic E (1994) Nasopharyngeal cancer: Epidemiology, staging, and treatment. Semin Oncol 21(3): 382397.

16. Berry MP, Smith CR, Brown TC, Jenkin RD K, Rider WD (2006) Nasopharyngeal carcinoma in the young. Int J Radiat Oncol Biol Phys 116(6): 415-421.

17. Commoun M, Vogt Hoerner, G Mourali N (1974) Tumors of the nasopharynx in Tunisia. An anatomic and clinical study based on 143 cases. Cancer 33(1): 184-192.

18. Levine PH, Connely RR, Easton JM (1980) Demographic patterns for nasopharyngeal carcinoma in the United States. Int J Cancer 26(6): 741-748.

19. Fernandez CH, Cangm A, Samaan NA, Rivera RA (1976) Nasopharyngeal carcinoma in children. Cancer 37: 2787-2791.

20. Pao WJ, Hustu HO, Douglass EC, Beckford NS, Kun LE (1989) Pediatric nasopharyngeal carcinoma: Long-term follow-up of 29 patients. Int J Radiat Oncol Biol Phys 17(2): 299-305.

21. Lombardi F, Gasparini M, Gianni C (1982) Nasopharyngeal carcinoma in childhood. Med Pediatr Oncol 10: 243-50.

22. Jereb B, Huvos EG, Steinherz P, Unal A (1980) Nasopharyngeal carcinoma in children Review of 16 cases. Int J Radiat Oncol Biol Phys 6: 487-491.

23. Roper HP, Essex-Cater A, Marsden HB (1986) Nasopharyngeal carcinoma in children. Pediatr Hematol Oncol 3: 143-152.

24. Baker SR, McClatchey KD (1981) Carcinoma of the nasopharynx in childhood. Head Neck Surg 89: 555-559.

25. Fernandez CH, Cangir A, Samaan NA, Rivera R (1976) Nasopharyngeal carcinoma in children. Cancer 37: 2787-2791.

26. Ghim TT, Briones M, Mason P, Crocker I, Davis P, et al. (1998) Effective adjuvant chemotherapy for advanced nasopharyngeal carcinoma in children: A final update for a long-term prospective study in a single institution. J Pediatr Hematol Oncol 20(2): 131-135.

27. Lobo-Sanahuja F, Garcia I, Carranza A, Cmacho A (1986) Treat- of tumors, ment and outcome of undifferentiated carcinoma of the nasopharynx in childhood: a 13-year experience. Med Pediatr Oncol 14: 6-11.

28. Mertens R, Karstens JH, Ammon J, Classen HWW, Mitter- mayer C (1984) Bisherige Erfahrungen der Interferontherapie an 7 Patienten mit NPC. Nasopharynx tumoren Munchen: Urban und Schwarzenberg 1984: 188-193. 


\section{Cancer Therapy \& Oncology International Journal}

29. Castro-Vita HC, Mendiondo DL, Shaw DL, Jelden G, Rene JB, et al. (1983) Nasopharyngeal carcinoma in the second decade of life. Radiology 148: 253-256.

30. Sarrazin D, Schwaab G, Fontaine F, Kalifa C, Richard J, et al. (1985) Radiotherapy of carcinoma of the nasopharynx in children after previous chemotherapy: preliminary results on 21 cases treated at the Institut Gustave-Roussy between1978 and 1981. Ann Otolaryngol Chir Cervicofac 102(3): 1175-1178.

31. Quin D, Yuhua H, Jiehuaa Y,Guozhen X, Weiming C, et al. (1988) Analysis of 1379 patients with nasopharyngeal carcinoma treated by radiation. Cancer 61(6): 1117-1124.

32. Gasparini M, Lombardi F, Rottoli L, Ballerini E, Morandi F (1988) Combined radiotherapy and chemotherapy in Stage T3 and T4 nasopharyngeal carcinoma in children. J Clin Oncol 6(3): 491-494.
33. Rottey S, Madani I, Deron P, Van Belle S (2011) Modern treatment for nasopharyngeal carcinoma: current status and prospects. Curr Opin Oncol 23(3): 254-258.

34. Caponigro F, Longo F, Ionna F, Perri F (2010) Treatment approaches to nasopharyngeal carcinoma: a review, Anticancer Drugs 21(5): 471 477.

35. Buehrlen CM Zwaan, B Granzen, L Lassay, P Deutz, P Vorwerk, et al. (2012) Multimodal treatment, including interferon beta, of nasopharyngeal carcinoma in children and young adults: preliminary results from the prospective, multicenter study NPC-2003-GPOH/ DCOG. Cancer 118(19): 4892-4900.

\begin{tabular}{l} 
Your next submission with Juniper Publishers \\
will reach you the below assets \\
- Quality Editorial service \\
- Swift Peer Review \\
- Reprints availability \\
- E-prints Service \\
- Manuscript Podcast for convenient understanding \\
- Global attainment for your research \\
- Manuscript accessibility in different formats \\
( Pdf, E-pub, Full Text, Audio) \\
- Unceasing customer service \\
Track the below URL for one-step submission \\
https://juniperpublishers.com/online-submission.php \\
\hline
\end{tabular}

